\title{
Impact of Different Water Repellent Finishes on Cotton Double Jersey Fabrics
}

\author{
Kawser Parveen Chowdhury \\ Department of Wet Process Engineering, Bangladesh University of Textiles, Dhaka, Bangladesh \\ Email: kpc.urmi@butex.edu.bd
}

How to cite this paper: Chowdhury, K.P. (2018) Impact of Different Water Repellent Finishes on Cotton Double Jersey Fabrics. Journal of Textile Science and Technology, 4, 85-99.

https://doi.org/10.4236/jtst.2018.43006

Received: May 19, 2018

Accepted: August 6, 2018

Published: August 9, 2018

Copyright $\odot 2018$ by author and Scientific Research Publishing Inc. This work is licensed under the Creative Commons Attribution International License (CC BY 4.0).

http://creativecommons.org/licenses/by/4.0/

(c) (i) Open Access

\begin{abstract}
This study demonstrated that the variation in physical and chemical performance on cotton double jersey knit fabrics was decided by the knit structure, water repellent chemicals types and their concentration. Here, two types of double jersey fabrics were treated with different types of water repellent chemicals at different formulations to evaluate the performance of water repellent finishes on knit fabrics properties. The levels of water repellency of the fabrics were assessed by AATCC 127 hydrostatic head test method and by ISO 4920:2012 spray rating test method. To evaluate the performance of water repellent finishes on knit fabric properties, GSM, bursting strength test according to ASTM (D 3786-87) method, air permeability, color fastness to wash, water, perspiration, chlorinated water and color fastness to rubbing with ISO method were done. The results showed that both physical and chemical properties of the finished cotton knits, depend to a great extent on knit structure, the water repellent finish type and concentration to obtain water repellent fabrics with desirable properties.
\end{abstract}

\section{Keywords}

Water Repellency, Water Repellent Finish, Double Jersey Fabric,

Fluorocarbon

\section{Introduction}

Cotton is an outstanding versatile fibre with superior quality mainly comfort ability. Water repellency is one general functional property that is required for protective clothing without deteriorating the comfort ability. Water repellent textiles have many uses such as industrial, consumer and apparel purpose. This repellency can be achieved by applying water repellent chemicals which imparts a thin surface layer of chemicals on textile fibres by the modification of surface 
energy of textiles without much deterioration of other mechanical and aesthetic properties like strength, flexibility, lustre, breathability, softness etc. [1]. It has been reported that various types of fluorochemicals that are used for textile finishing, mainly used to impart water repellency along with oil repellency [2] [3] [4] [5] [6]. These consists of perfluorinated carbon chains with a polymer backbone with perfluoro groups as its side chains [7]. Some existing fluorochemicals are made with $\mathrm{C} 8$ carbon in the polymer backbone chains which after using a certain time can release perfluorooctanesulfonate (PFOS) and perfluorooctanoic acid (PFOA) and other toxic and hazardous materials. Hence C6 based fluorocarbons were introduced to minimize the toxicity, though their repellency as well as longevity is less than $\mathrm{C} 8$ based ones. Fluorochemical finishings are generally used to fabric by the pad-dry-cure method with an elevated curing temperature around $160^{\circ} \mathrm{C}-170^{\circ} \mathrm{C}$ for a couple of minutes [2] [3] [4] [5]. The water repellent properties were evaluated by measuring contact angle, wettability, moisture absorption and vapour permeability.

The first group of water repellent finishing agents is dispersion of fluorine compounds, namely fluorocarbon (FC). The final polymer, when applied to a fibre, should form a structure that presents a dense CF3 outer surface for maximum repellency. A typical structure is shown in below Figure 1. The length of the perfluorinated side chains should be about 8 - 10 carbons. Co-monomers are $\mathrm{X}, \mathrm{Y}$, for example are stearyl- or lauryl-meth-acrylate, butyl-acrylate, methylolor epoxy-functional acrylates.

The second group water repellent chemical is fluorocarbon resin with polymeric, hyperbranched dendrimers in a hydrocarbon. It is a novel FC development, is inspired by nature and therefore called bio-nic finishes. Fluorocarbon polymers are applied together with dendrimers. Dendrimers are highly branched oligomers with non-polar chains forming a starbrush structure (Figure 2). The resulting polar and non-polar sandwich arrangements are highly ordered, causing better repellency effects, with lower no of fluorocarbon (C6) compared to dendrimer-free FC finishes.

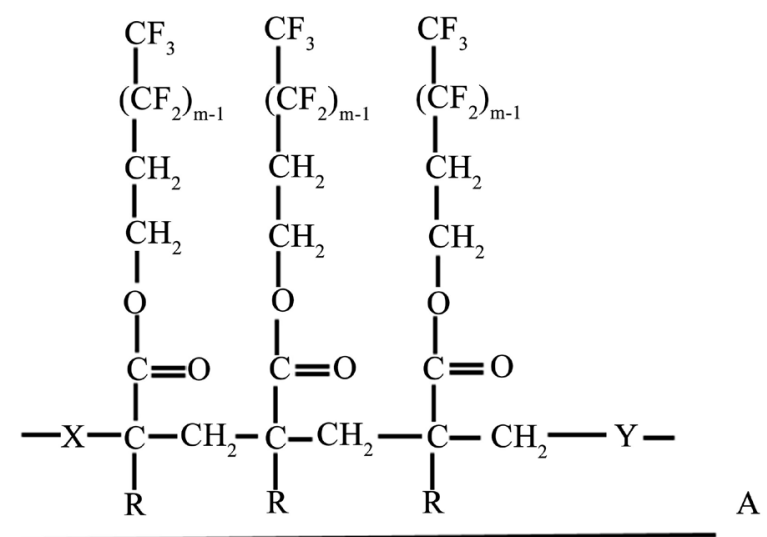

Figure 1. Fluorocarbon repellent on fibre surface. $M=6-10 . \mathrm{X}$ and $\mathrm{Y}$ are co-monomers, mainly stearylates. $\mathrm{R}=\mathrm{H}$ or $\mathrm{CH}_{3}$ (polyacrylic or polymethacrylic acid esters). A is the fibre surface [8]. 


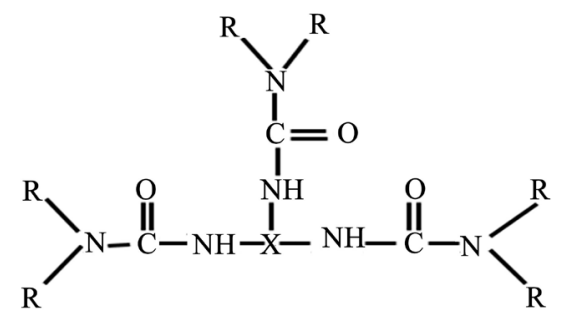

$$
\mathrm{R}=-\stackrel{\mathrm{O}}{\mathrm{C}}-\mathrm{C}_{17} \mathrm{H}_{35} \quad \text { or }-\left(\mathrm{CH}_{2}\right)_{\mathrm{n}} \stackrel{\mathrm{NHC}}{\text { II }}-\mathrm{C}_{17} \mathrm{H}_{35}
$$

Figure 2. A dendrimer structure synthesized from three distearyl-amines or amides and a trifunctional isocyanate $\mathrm{X}(\mathrm{N}=\mathrm{C}=\mathrm{O})[8]$.

Third group water repellent chemical structure is same as first one but fluorocarbon with isocyanate booster and the length of the perfluorinated side chains should be about 6 carbons. [8]

In the literature, some of researches on different water repellent chemicals, their application procedure, curing temperature, their durability and different wash fastness have been evaluated. [9] [10] There are almost unadequate work on the performance of water repellent finish and their effects on different properties of knit double jersey fabrics. The purpose of this study was to investigate and evaluate the performance of what water repellent finish on which concentration (conc.) affected different double jersey knit fabric properties after finishing.

\section{Materials and Methods}

\subsection{Materials}

\subsubsection{Fabrics}

In this experiment, $100 \%$ cotton double jersey knit fabrics (scoured and bleached) were used. At first fabric is finished with different types of water repellent chemicals by pad-dry-cure method. The fabrics were supplied by Essential Clothing Ltd, Bangladesh. Two types of double jersey fabrics were used here, one is rib $(1 \times 1)$ and another is interlock. Fabric specifications were given in Table 1.

Supplied fabrics which presents good hydrophilic character were first finished by using three different fluorocarbon based water repellent chemicals in three different concentrations $(70 \mathrm{~g} / \mathrm{L}, 90 \mathrm{~g} / \mathrm{L}$ and $100 \mathrm{~g} / \mathrm{L})$ to analyze the performance of different water repellent chemicals and their varying concentration on water repellency and other physical properties of the fabrics. In addition, fabrics were dyed by using following recipe which is given in Table 2 in Micro Fibre lab and finished with different water repellent chemicals in $100 \mathrm{~g} / \mathrm{L}$ concentration (conc.) as it showed excellent water repellency to investigate different fastness properties of the finished fabrics.

Dye application bath for double jersey fabrics 
Table 1. Types of double jersey fabrics with their specification.

\begin{tabular}{ccccl}
\hline Name of Fabric & Type of Knit structure & GSM & Count & Composition \\
\hline \multirow{2}{*}{ Double jersey } & Rib $(1 \times 1)$ & 315 & $30 \mathrm{Ne}$ & $100 \%$ cotton \\
& Interlock & 220 & $30 \mathrm{Ne}$ & $100 \%$ cotton \\
\hline
\end{tabular}

Table 2. Dye application bath of double jersey fabrics are listed.

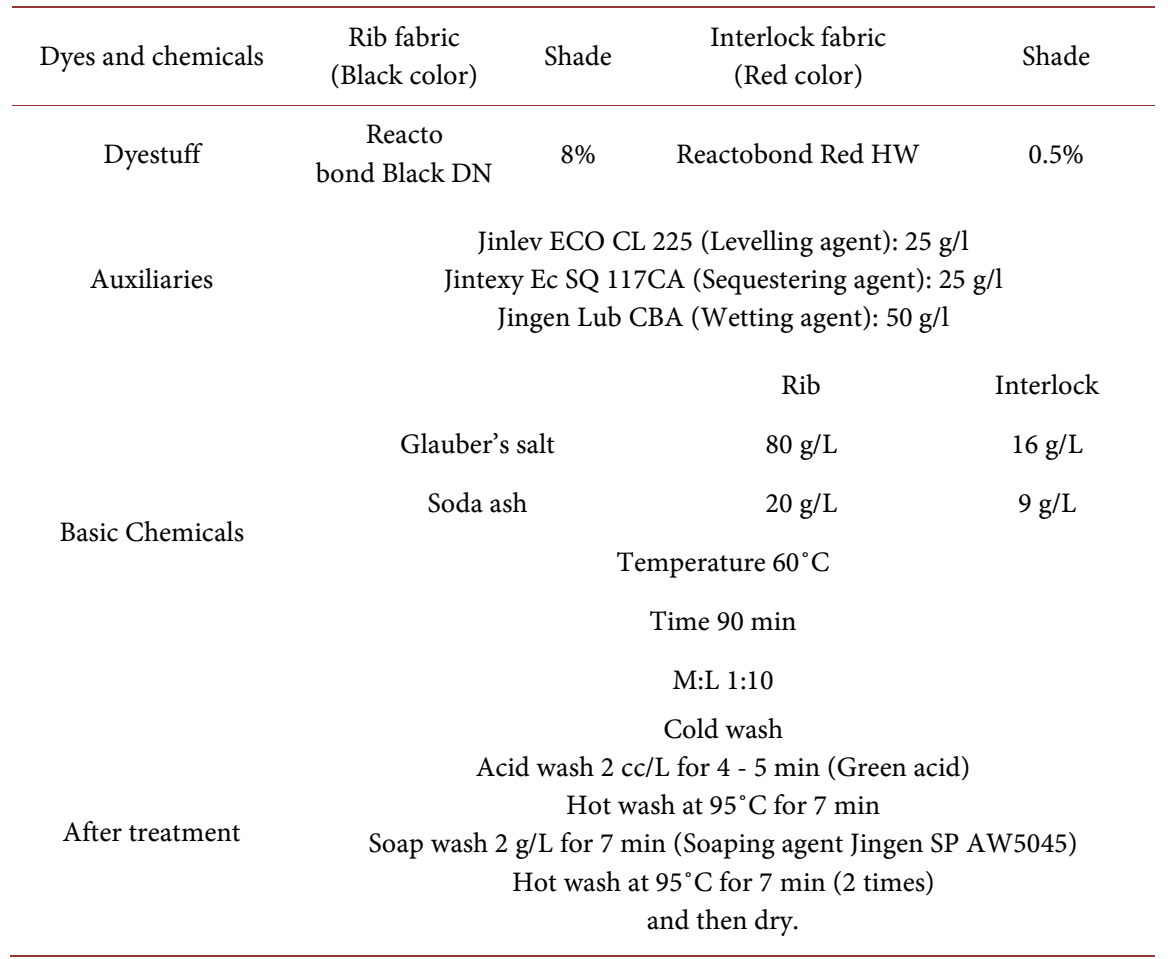

\subsubsection{Water Repellent Chemicals}

Three types of fluorocarbon based water repellent chemicals are used, first is fluorocarbon (FC) (trade name Nuva TTC, dispersion of fluorine compound, weakly cationic, Clariant), second is fluorocarbon with dendrimers $(\mathrm{FC}+\mathrm{D})$ (trade name Rucostar EEE6, fluorocarbon (C6) resin with polymeric, hyperbranched dendrimers in a hydrocarbon, weakly cationic, Rudolf chemie) and third is fluorocarbon with booster $(\mathrm{FC}+\mathrm{B}$ ) (trade name Lurotex protector RP ECO, C6 fluorocarbon finish with an unblocked isocyanate booster, weakly cationic, BASF).

\subsubsection{Water Repellent Application Bath}

Two types of double jersey derivative fabrics were treated with three different water repellent chemicals at three different conc. $(70 \mathrm{~g} / \mathrm{L}, 90 \mathrm{~g} / \mathrm{L}$ and $100 \mathrm{~g} / \mathrm{L})$ from a separate bath with same bath condition. Fluorocarbon (FC), fluorocarbon with dendrimers $(\mathrm{FC}+\mathrm{D})$ and fluorocarbon with booster $(\mathrm{FC}+\mathrm{B})$ water repellent chemical's solutions were prepared. The process parameters were adopted as recommended by the supplier and bath set up are given in Table 3. Horizontal Pad-Mangle machine (Rapid, Xiamen Rapid Co Ltd, China) was used 
Table 3. Water repellent application bath.

\begin{tabular}{|c|c|c|c|c|}
\hline \multicolumn{2}{|c|}{ Finishing bath set up } & FC & $\mathrm{FC}+\mathrm{D}$ & $\mathrm{FC}+\mathrm{B}$ \\
\hline \multirow{3}{*}{$\begin{array}{c}\text { Name } \\
\text { of chemicals }\end{array}$} & Resin & $\begin{array}{c}70,90,100 \mathrm{~g} / \mathrm{L} \\
\text { of fluorocarbon } \\
\text { resin }\end{array}$ & $\begin{array}{l}70,90,100 \mathrm{~g} / \mathrm{L} \\
\text { of fluorocarbon } \\
\text { with dendrimers } \\
\text { resin }\end{array}$ & $\begin{array}{c}70,90,100 \mathrm{~g} / \mathrm{L} \\
\text { of fluorocarbon } \\
\text { with booster } \\
\text { resin }\end{array}$ \\
\hline & Acetic acid & $\begin{array}{l}01 \mathrm{ml} / \mathrm{L} \text { as } \\
\text { required for } \\
\mathrm{p}^{\mathrm{H}} 4-5\end{array}$ & $\begin{array}{l}01 \mathrm{ml} / \mathrm{L} \text { as } \\
\text { required for } \\
\mathrm{p}^{\mathrm{H}} 4-5\end{array}$ & $\begin{array}{c}01 \mathrm{ml} / \mathrm{L} \text { as } \\
\text { Required for } \\
\mathrm{p}^{\mathrm{H}} 4-5\end{array}$ \\
\hline & $\begin{array}{c}\text { Perapret Booster } \\
\text { XLR }\end{array}$ & -- & -- & $\begin{array}{l}8 \% \text { of the of fluo- } \\
\text { rocarbon } \\
\text { dosage }\end{array}$ \\
\hline \multirow{4}{*}{$\begin{array}{l}\text { Application } \\
\text { Parameters }\end{array}$} & Padding & & $80 \%$ pick up & \\
\hline & Drying & & $120^{\circ} \mathrm{C}$ for $3 \mathrm{~min}$ & \\
\hline & Curing & & $160^{\circ} \mathrm{C}$ for $2 \mathrm{~min}$ & \\
\hline & Padder Pressure & & $2.3 \mathrm{~kg} / \mathrm{cm}^{2}$ & \\
\hline
\end{tabular}

for padding with $4.5 \mathrm{rpm}$ fabric speed and $2.3 \mathrm{~kg} / \mathrm{cm}^{2}$ padding pressure. Channel precision oven machine, made in China, was used for drying and Labtec Steamer machine (Newave Lab equipments Co Ltd, Taiwan) was used for curing.

\subsection{Methods}

\subsubsection{Water Repellent Evaluation Test}

1) Drop test: It checked the contact angle by using AATCC 79 method. ( one water droplet is placed on treated fabric from specific distance and checked the droplet visually to evaluate the water repellency. When water droplet is placed on finished fabric then the drop will rest up on it and will not penetrate it means that the finished material surface has lower surface tension than water surface tension, then that material is called water repellent.)

2) Spray rating test: The spray rating tests were evaluted by using ISO 4920:2012 test method.

3) Hydrostatic Head Test: It was done by Shirley hydrostatic head tester, England according to AATCC 127 method.

\subsubsection{Physical and Chemical Testing}

Each samples were tested in the standard atmosphere, $25^{\circ} \mathrm{C} \pm 2^{\circ} \mathrm{C}$ temperature and 65\% RH after conditioning $24 \mathrm{hrs}$.

1) GSM test: GSM test was done by GSM cutter from James H. Heal \& Co. Ltd. Halifax, England according to ASTM (D 3776-79) method.

2) Bursting strength test: It was done by bursting strength tester from SDL Atlas according to ASTM (D 3786-87) method.

3) Air permeability test: It is done by using Textest FX 3300 Labair air permeability tester, Textest Instrument, Switzerland according to ISO 9237 method.

4) Color fastness to wash: Color fastness to wash was measured with ISO$105 \mathrm{C} 2 \mathrm{~S}$ method. 
5) Color fastness to water: It is done by ISO 105-E01 method.

6) Color fastness to chlorinated water: It is done by ISO 105-E03 method

7) Color fastness to perspiration: It is done by ISO 105-E04 method

8) Color fastness to rubbing: The resistance of color against rubbing of dyed fabrics (dry and wet) were evaluated with ISO-105-X 12 method.

\section{Result and Discussion}

\subsection{Water Repellent Evaluation Test}

\subsubsection{Drop Test}

Three fluorocarbon based water repellent solutions (trade name Nuva TTC, Rcostar EEE6 and Lurotex protector RP ECO) were prepared in 70 g/L, 90 g/L and $100 \mathrm{~g} / \mathrm{L}$ conc. and applied these conc. on different $100 \%$ cotton double jersey knit fabrics. Two different double jersey knit fabrics were used in here which were $1 \times 1$ rib and interlock.

This is the visual test to evaluate the water repellency. If the material surface has lower surface tension than water surface tension, then that material is called water repellent. When water drop is placed on water repellent material then the drop will rest up on it and will not penetrate, then it will be called water repellent.

Here are some physical appearances of untreated and treated rib and interlock fabrics by using fluorocarbon with dendrimer chemicals (trade name is Rcostar EEE6 and expressed by FC + D) (Figure 3), showed that treated fabrics are water repellent and pictures were taken by using Projectina (Electron microscope) dmm-2000 model. 1) Untreated black color dyed of rib fabric; 2) Black color dyed of rib fabric, treated with FC $+\mathrm{D}$ chemicals at $100 \mathrm{~g} / \mathrm{L}$ conc; 3) Untreated pink color dyed of interlock fabric; 4) Pink color dyed of interlock fabric, treated with FC $+\mathrm{D}$ chemicals at $100 \mathrm{~g} / \mathrm{L}$ conc. (untreated fabric showed absorbing area of water droplet and treated fabric showed water droplet without penetration); 5) Untreated white rib fabric; 6) Treated white rib fabric with $70 \mathrm{~g} / \mathrm{L}$ conc. of FC + D chemical; 7) Treated white rib fabric with $90 \mathrm{~g} / \mathrm{L}$ conc. of FC + D chemical; 8) Treated white rib fabric with $100 \mathrm{~g} / \mathrm{L}$ conc. of FC + D chemical; 9) Untreated white interlock fabric; 10) Treated white interlock fabric with $70 \mathrm{~g} / \mathrm{L}$ conc. of FC $+\mathrm{D}$ chemical; 11) Treated white interlock fabric with $90 \mathrm{~g} / \mathrm{L}$ conc. of FC + D chemical; 12) Treated white interlock fabric with $100 \mathrm{~g} / \mathrm{L}$ conc. of FC + D chemical;

\subsubsection{Spray Rating Test}

$\mathrm{FC}, \mathrm{FC}+\mathrm{D}$ and $\mathrm{FC}+\mathrm{B}$ water repellent chemical's solutions were prepared in 70 $\mathrm{g} / \mathrm{L}, 90 \mathrm{~g} / \mathrm{L}$ and $100 \mathrm{~g} / \mathrm{L}$ conc. and applied on double jersey knit dyed fabrics. These treated fabrics were evaluated using ISO 4920:2012 method. The evaluated rating of the samples are given in chart with its graphical analysis. Schindler et al described that after completing the pad-dry-cure process, perfluoro side chains changed to almost crystalline structures by curing process to achieve optimal water repellency [8]. Compared with the untreated fabric, the finished fabrics 
had good water repellency with around 3 - 5 grades.

It is shown from Figure 4 and Table 4 that by applying $70 \mathrm{~g} / \mathrm{L}$ conc., water repellency rating varies with different double jersey fabrics. FC + D water repellent chemical and rib fabric give comparatively better repellency for its compactness and for its heavy GSM. In $90 \mathrm{~g} / \mathrm{L}$ conc., water repellency rating has improved for FC + B water repellent chemical. Among the fabric, heavy GSM of rib fabric show the best rating. FC $+\mathrm{D}$ water repellent chemical's treated fabrics remain same rating like $70 \mathrm{~g} / \mathrm{L}$ conc. treated fabric though $\mathrm{FC}$ water repellent chemical improves by $90 \mathrm{~g} / \mathrm{L}$ conc. Particularly for $100 \mathrm{~g} / \mathrm{L}$ conc., both FC and $\mathrm{FC}+\mathrm{D}$ gives the best result for all fabrics and in high conc. all the chemicals show better result for both fabrics.

\subsubsection{Hydrostatic Head Test}

The hydrostatic head test was done according to AATCC 127 method on double jersey fabrics after water repellent finish at various conc. which are stated below in Figure 5.

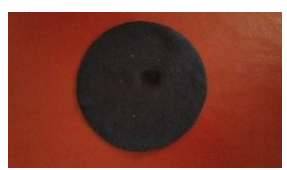

(a)

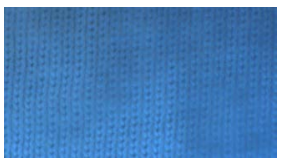

(e)

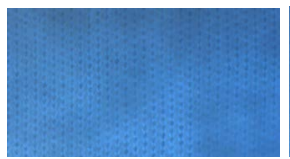

(i)

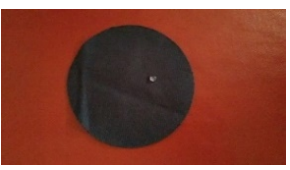

(b)

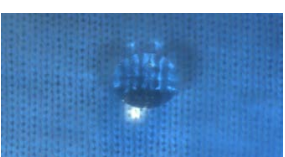

(f)

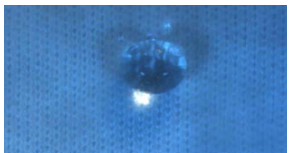

(j)

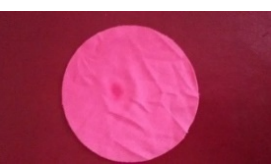

(c)

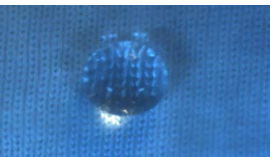

(g)

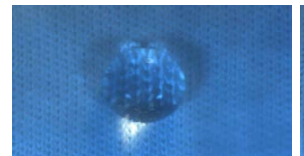

(k)

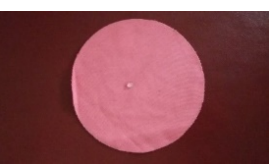

(d)

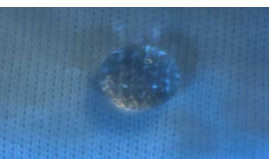

(h)

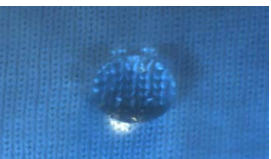

(I)

Figure 3. Some physical appearances of untreated and treated fabrics.

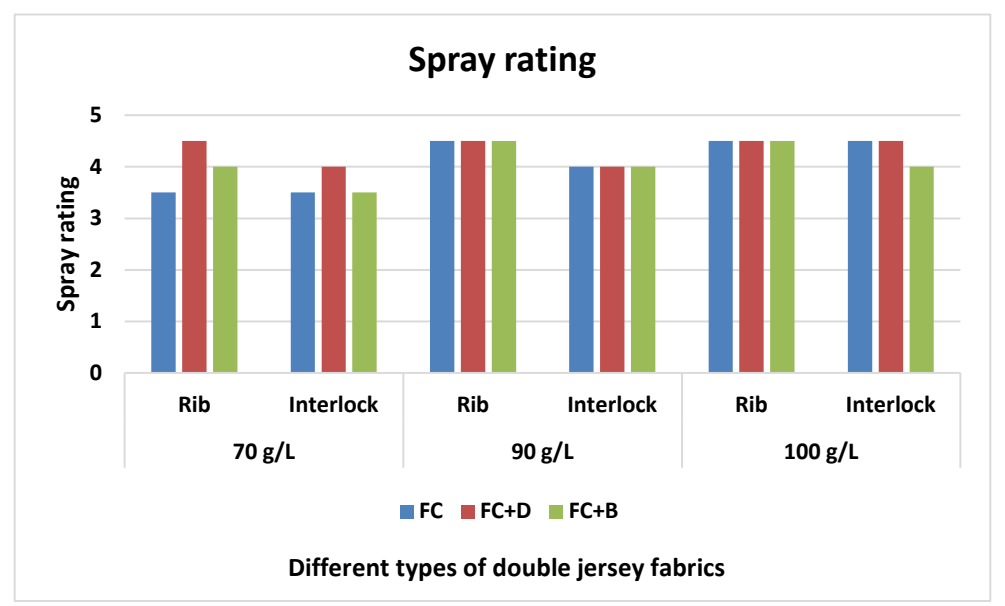

Figure 4. Spray rating of double jersey fabrics treated with water repellent chemicals at $70 \mathrm{~g} / \mathrm{L}, 90 \mathrm{~g} / \mathrm{L}$ and $/ \mathrm{L}$ conc. 


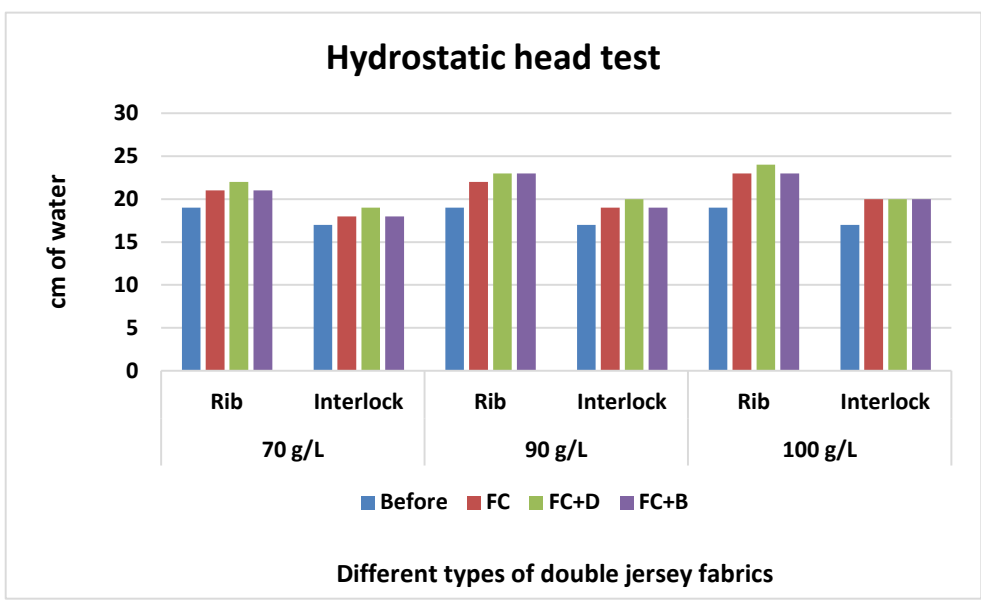

Figure 5. The hydrostatic head test of double jersey fabrics treated with water repellent chemicals at $70 \mathrm{~g} / \mathrm{L}, 90 \mathrm{~g} / \mathrm{L}$ and $100 \mathrm{~g} / \mathrm{L}$ conc.

Table 4. Spray rating of double jersey fabrics treated with water repellent chemicals at 70 $\mathrm{g} / \mathrm{L}, 90 \mathrm{~g} / \mathrm{L}$ and $100 \mathrm{~g} / \mathrm{L}$ conc.

\begin{tabular}{ccccc}
\hline $\begin{array}{c}\text { Double jersey } \\
\text { fabrics }\end{array}$ & Conc. (g/L) & FC & FC + D & FC + B \\
\hline Rib & 70 & 3.5 & 4.5 & 4 \\
Interlock & & 3.5 & 4 & 3.5 \\
Rib & 90 & 4.5 & 4.5 & 4.5 \\
Interlock & & 4.5 & 4.5 & 4 \\
Rib & 100 & 4.5 & 4.5 & 4.5 \\
Interlock & & & & 4 \\
\hline
\end{tabular}

From the above chart it has clearly seen that the more pressure is required to force water through the fabric. After gradually increasing the conc. from $70 \mathrm{~g} / \mathrm{L}$ to $100 \mathrm{~g} / \mathrm{L}$, the pressure requires more. Rib fabric has higher hydrostatic head test rating than interlock fabric because of rib fabric has higher GSM and more compactness. An increase in repellent conc. caused an increase in wetting times of the fabric after finishing. In all conc., FC $+\mathrm{D}$ water repellent chemical shows better hydrostatic head test rating than $\mathrm{FC}+\mathrm{B}$ and $\mathrm{FC}$ water repellent chemicals for both rib and double jersey fabrics. Because the water repellent chemicals form a coating on the fabric and the more conc. of chemicals leads the higher density of the coating resulting increased water repellency.

\subsection{Analysis of GSM}

The GSM tests were done according to ASTM (D 3776-79) method for fabrics with different conc. The chart has given below:

After chemical implementation of different double jersey knit fabrics with different water repellents at various conc. are stated above Figure 6 and Table 5. GSM has increased because chemical has covered up all the pores of the fabric and a chemical coating is created on the fabric. Therefore, the water is not al- 
lowed to penetrate into the fabric. GSM increases gradually after increasing the conc. of different water repellents from $70 \mathrm{~g} / \mathrm{L}$ to $100 \mathrm{~g} / \mathrm{L}$. Because the water repellent chemicals form a coating on the fabric and the more conc. of chemicals leads the higher density of the coating which results higher water repellency.

\subsection{Bursting Strength Test}

Bursting strength plays a significant role after water repllent finish. It was done according to ASTM (D 3786-87) method. From the Table 6 and Figure 7, the bursting strength of the cotton double jersey fabrics are reduced and it's reasonable. The bursting strength of knit fabric reduced because of effect of the cellulosic fiber during cross linking process. As resin crosslinks in amorphous region of cellulose leading lower flexibility and harsh handfeel. Though it is marginal to go for the next proceedings.

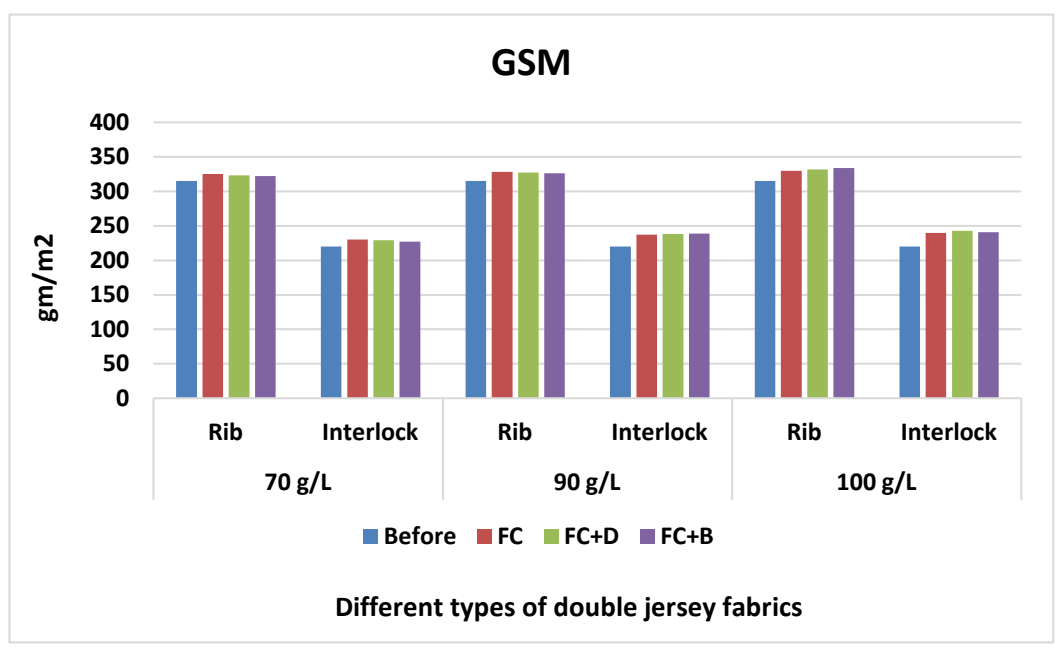

Figure 6. GSM of double jersey fabrics treated with water repellent chemicals at 70 $\mathrm{g} / \mathrm{L}, 90 \mathrm{~g} / \mathrm{L}$ and $100 \mathrm{~g} / \mathrm{L}$ conc.

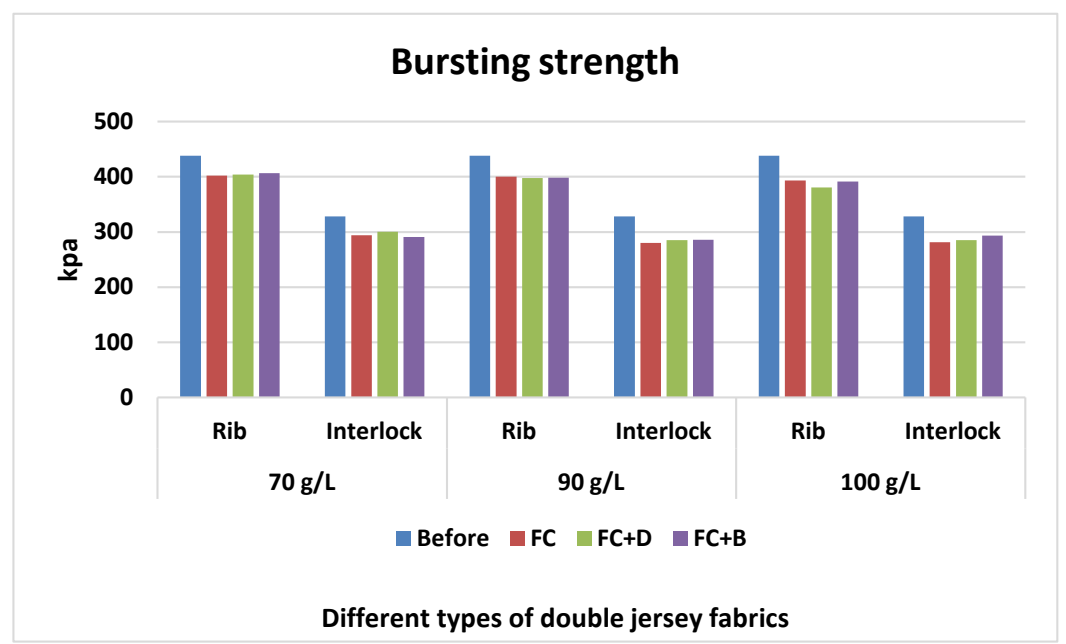

Figure 7. Bursting Strength (kpa) of double jersey fabrics treated with water repellent chemicals at conc. $70 \mathrm{~g} / \mathrm{L}, 90 \mathrm{~g} / \mathrm{L}$ and $100 \mathrm{~g} / \mathrm{L}$. 
Table 5. GSM of double jersey fabrics treated with water repellent chemicals at $70 \mathrm{~g} / \mathrm{L}, 90$ $\mathrm{g} / \mathrm{L}$ and $100 \mathrm{~g} / \mathrm{L}$ conc.

\begin{tabular}{cccccc}
\hline $\begin{array}{c}\text { Double jersey } \\
\text { fabrics }\end{array}$ & $\begin{array}{c}\text { Conc. } \\
(\mathrm{g} / \mathrm{L})\end{array}$ & GSM (before) & FC & FC + D & FC + B \\
\hline Rib & 70 & 315 & 325 & 323 & 322 \\
Interlock & 220 & 230 & 229 & 227 \\
Rib & 315 & 328 & 327 & 326 \\
Interlock & 90 & 220 & 237 & 238 & 239 \\
Rib & 100 & 315 & 330 & 332 & 334 \\
Interlock & & 220 & 240 & 243 & 241 \\
\hline
\end{tabular}

Table 6. Bursting strength of double jersey fabrics treated with water repellent chemicals at $70 \mathrm{~g} / \mathrm{L}, 90 \mathrm{~g} / \mathrm{L}$ and $100 \mathrm{~g} / \mathrm{L}$ conc.

\begin{tabular}{cccccc}
\hline Double jersey fabrics & $\begin{array}{c}\text { Conc. } \\
(\mathrm{g} / \mathrm{L})\end{array}$ & $\begin{array}{c}\text { Bursting Strength } \\
(\mathrm{kpa}) \text { (before) }\end{array}$ & FC & FC + D & FC + B \\
\hline Rib & 70 & 438.1 & 402.0 & 403.7 & 406.3 \\
Interlock & 328.3 & 294.2 & 300.5 & 290.7 \\
Rib & 90 & 438.1 & 400.5 & 397.8 & 398.3 \\
Interlock & & 328.3 & 280.3 & 284.9 & 285.5 \\
Rib & 100 & 438.1 & 393.4 & 380.7 & 391.2 \\
Interlock & & 328.3 & 281.1 & 285.4 & 293.3 \\
\hline
\end{tabular}

The fabric's strength is decreased by increasing of concentration. When the water repellent chemicals form cross link with the cotton free $\mathrm{O}-\mathrm{H}$ group in the amorphous region, it makes stiff of the fabric and moreover, cross linking reaction is done mainly in acidic condition which are also responsible for the reduction of the bursting strength.

\subsection{Air Permeability Test}

It was done by using ISO 9237 method. The air permeability of double jersey fabrics decreased via water repellent finish which are stated in Table 7 and Figure 8. Changing conc. from lower to higher conc., gives gradually decreased air permeability, regardless of repellent chemical type. This may be because of the formation of crosslinking networks after finish. The thin film formation on the surface of fabric after finishing, tighter constructions and small pore dimensions are some of the factors that affect the lower air permeability. Modify the fabric structure along with entrapping the air inside the fabric structure is mainly responsible for the reduction of air permeability. Air permeability rating of FC $+\mathrm{B}$ for both rib and interlock fabrics gave comparatively better result than FC and $\mathrm{FC}+\mathrm{D}$ water repellent chemicals. 


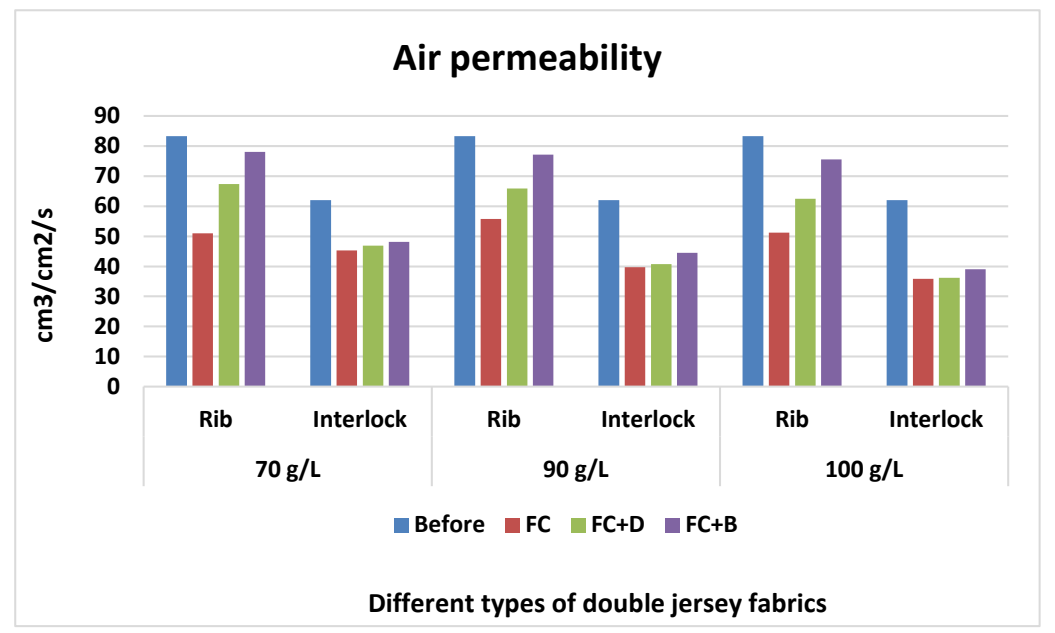

Figure 8. Air permeability of double jersey fabrics treated with water repellent chemicals at $70 \mathrm{~g} / \mathrm{L}, 90 \mathrm{~g} / \mathrm{L}$ and $100 \mathrm{~g} / \mathrm{L}$ conc.

Table 7. Air permeability of double jersey fabrics treated with water repellent chemicals at $70 \mathrm{~g} / \mathrm{L}, 90 \mathrm{~g} / \mathrm{L}$ and $100 \mathrm{~g} / \mathrm{L}$ conc.

\begin{tabular}{cccccc}
\hline Double jersey fabrics & $\begin{array}{c}\text { Conc. } \\
(\mathrm{g} / \mathrm{L})\end{array}$ & $\begin{array}{c}\text { Air permeability } \\
\left(\mathrm{cm}^{3} / \mathrm{cm}^{2} / \mathrm{s}\right) \text { (before) }\end{array}$ & FC & FC + D & FC + B \\
\hline Rib & 70 & 83.3 & 51.0 & 67.4 & 78.1 \\
Interlock & 62.0 & 45.3 & 46.9 & 48.2 \\
Rib & 90 & 83.3 & 55.8 & 65.9 & 77.1 \\
Interlock & 62.0 & 39.7 & 40.7 & 44.5 \\
Rib & 100 & 83.3 & 51.2 & 62.5 & 75.6 \\
Interlock & & 62.0 & 35.9 & 36.2 & 39.0 \\
\hline
\end{tabular}

\subsection{Color Fastness to Wash}

The wash fastness of water repellent treated fabric with $100 \mathrm{~g} / \mathrm{L}$ conc. is rated under grey scale for two types of measurement, one is for color change and another is for color staining. Color fastness to wash was measured with ISO105/C06-C2S method.

The wash fastness of all water repellent chemicals are measured at $100 \mathrm{~g} / \mathrm{L}$ conc. as it showed the best water repellency and physical properties compared with other concentrations. From Table 8, the wash fastness of FC, FC + B and $\mathrm{FC}+\mathrm{D}$ water repellent chemicals shows better result than untreated one for rib fabric. But the wash fastness is slightly decreased for FC, FC + B and FC + D water repellent chemicals than untreated one for interlock fabric. The improvement of wash fastness of water repellent finish is because of the dye molecules trapped inside the crosslinking film.

\subsection{Color Fastness to Water}

To investigate the effect of water fastness of water repellent treated fabrics are 
rated under grey scale for two types of measurement, one is for color change and another is for color staining. It is done by ISO 105-E01 method. The rated chart is given below in Table 9.

The water fastness of FC and FC $+\mathrm{B}$ water repellent chemicals reduced than untreated one though $\mathrm{FC}+\mathrm{D}$ chemicals remained unchanged for rib fabric. Water fastness remained unchanged for FC, FC $+\mathrm{D}$ and $\mathrm{FC}+\mathrm{B}$ chemicals for interlock fabric. The improvement of wash fastness of water repellent finish is because of the dye molecules trapped inside the crosslinking film.

\subsection{Color Fastness to Chlorinated Water}

To evaluate the effect of chlorinated water fastness of treated fabrics are rated under grey scale for color change. The rated chart is given below in Table 10 . Color fastness to chlorinated water is done by ISO 105-E03 method. The chlorinated water fastness of all water repellent chemicals were measured at $100 \mathrm{~g} / \mathrm{L}$ conc. The chlorinated water fastness of all chemicals slightly decreases than untreated one except FC + D water repellent chemicals for rib fabric.

\subsection{Color Fastness to Perspiration}

The resistance of color against acid and alkali of dyed fabrics are done by ISO 105-E04 method. The rated chart is given below in Table 11. The fastness to perspiration of all water repellent chemicals are measured at $100 \mathrm{~g} / \mathrm{L}$ conc. The fastness to perspiration of all water repellent chemical shows better result than untreated one for all double jersey fabrics.

\subsection{Rubbing Fastness}

The rubbing fastness of water repellent treated dyed fabrics are rated under grey scale for the measurement of color staining against dry and wet white fabric. The rated chart of rubbing fastness for wet and dry rub are given below in Table 12. It shows that both dry and wet rub are remain same or slightly increased after water repellent finish on conc. $100 \mathrm{~g} / \mathrm{L}$ than untreated one as water repellent chemical make a thin coating on fabric surface.

\section{Conclusion}

In this study, the effect of water repellent finishes on double jersey structured knit fabrics and water repellent chemicals conc. on the water repellency of the fabrics were investigated. To do so, 36 repellent treated different structured knit fabrics samples were tested and obtained results were evaluated. Different physical and chemical test results showed that the repellent types and their conc. ranges significantly influenced water repellency of double jersey knit fabrics. For water repellent finishing, the variation in the water repellency performance and comfort properties of treated cotton fabrics is mainly depends on their structure and chemical's add on. When fluorocarbon with dendrimers $(F C+D)$ was used, then the best water repellency is obtained. Changing conc. from lower to higher 
Table 8. Color fastness to wash of double jersey fabrics treated with water repellent chemicals at $100 \mathrm{~g} / \mathrm{L}$ conc.

\begin{tabular}{|c|c|c|c|c|c|c|c|c|c|c|c|c|}
\hline \multicolumn{13}{|c|}{ Color fastness to wash } \\
\hline \multirow{2}{*}{ Fabric } & \multicolumn{3}{|c|}{ Unfinished } & \multicolumn{3}{|c|}{ FC } & \multicolumn{3}{|c|}{$\mathrm{FC}+\mathrm{D}$} & \multicolumn{3}{|c|}{$\mathrm{FC}+\mathrm{B}$} \\
\hline & $\begin{array}{l}\text { Color } \\
\text { change }\end{array}$ & Cotton & Wool & $\begin{array}{l}\text { Color } \\
\text { change }\end{array}$ & Cotton & Wool & $\begin{array}{l}\text { Color } \\
\text { change }\end{array}$ & Cotton & Wool & $\begin{array}{l}\text { Color } \\
\text { change }\end{array}$ & Cotton & Wool \\
\hline Rib & 4 & 3 & 4 & 4 & $3-4$ & 4 & 4 & $3-4$ & 4 & 4 & 4 & 4 \\
\hline Interlock & 4 & $3-4$ & 4 & $3-4$ & $3-4$ & 4 & $3-4$ & $3-4$ & 4 & $3-4$ & $3-4$ & 4 \\
\hline
\end{tabular}

Table 9. Color fastness to water of double jersey fabrics treated with water repellent chemicals at $100 \mathrm{~g} / \mathrm{L}$ conc.

\begin{tabular}{|c|c|c|c|c|c|c|c|c|c|c|c|c|}
\hline \multicolumn{13}{|c|}{ Color fastness to water } \\
\hline \multirow{2}{*}{ Sample } & \multicolumn{3}{|c|}{ Unfinished } & \multicolumn{3}{|c|}{$\mathrm{FC}$} & \multicolumn{3}{|c|}{$\mathrm{FC}+\mathrm{D}$} & \multicolumn{3}{|c|}{$\mathrm{FC}+\mathrm{B}$} \\
\hline & $\begin{array}{l}\text { Color } \\
\text { change }\end{array}$ & Cotton & Wool & $\begin{array}{l}\text { Color } \\
\text { change }\end{array}$ & Cotton & Wool & $\begin{array}{l}\text { Color } \\
\text { change }\end{array}$ & Cotton & Wool & $\begin{array}{l}\text { Color } \\
\text { change }\end{array}$ & Cotton & Wool \\
\hline Rib & $4-5$ & $4-5$ & $4-5$ & $4-5$ & 4 & $4-5$ & $4-5$ & $4-5$ & $4-5$ & $4-5$ & 4 & $4-5$ \\
\hline Interlock & $4-5$ & $4-5$ & $4-5$ & $4-5$ & $4-5$ & $4-5$ & $4-5$ & $4-5$ & $4-5$ & $4-5$ & $4-5$ & $4-5$ \\
\hline
\end{tabular}

Table 10. Color fastness to chlorinated water of double jersey fabrics treated with water repellent chemicals at $100 \mathrm{~g} / \mathrm{L}$ conc.

\begin{tabular}{ccccc}
\hline & \multicolumn{4}{c}{ Color fastness to chlorinated water } \\
\hline Sample & Unfinished & FC & FC + D & FC + B \\
\cline { 2 - 5 } & Color change & Color change & Color change & Color change \\
Rib & 4 & $3-4$ & 4 & $3-4$ \\
Interlock & 4 & $3-4$ & $3-4$ & $3-4$ \\
\hline
\end{tabular}

Table 11. Color fastness to perspiration of double jersey fabrics treated with water repellent chemicals at $100 \mathrm{~g} / \mathrm{L}$ conc.

\begin{tabular}{|c|c|c|c|c|c|c|c|c|c|c|c|c|}
\hline \multicolumn{13}{|c|}{ Color fastness to perspiration } \\
\hline \multirow{3}{*}{ Sample } & \multicolumn{3}{|c|}{ Unfinished } & \multicolumn{3}{|c|}{ FC } & \multicolumn{3}{|c|}{$\mathrm{FC}+\mathrm{D}$} & \multicolumn{3}{|c|}{$\mathrm{FC}+\mathrm{B}$} \\
\hline & \multirow{2}{*}{$\begin{array}{l}\text { Color } \\
\text { change }\end{array}$} & \multicolumn{2}{|c|}{ Color staining } & \multirow{2}{*}{$\begin{array}{l}\text { Color } \\
\text { change }\end{array}$} & \multicolumn{2}{|c|}{ Color staining } & \multirow{2}{*}{$\begin{array}{l}\text { Color } \\
\text { change }\end{array}$} & \multicolumn{2}{|c|}{ Color staining } & \multirow{2}{*}{$\begin{array}{l}\text { Color } \\
\text { change }\end{array}$} & \multicolumn{2}{|c|}{ Color staining } \\
\hline & & Acid & Alkali & & Acid & Alkali & & Acid & Alkali & & Acid & Alkali \\
\hline Rib & 4 & $3-4$ & 4 & $4-5$ & 4 & $4-5$ & $4-5$ & 4 & $4-5$ & $4-5$ & 4 & $4-5$ \\
\hline Interlock & $4-5$ & $4-5$ & $4-5$ & $4-5$ & $4-5$ & $4-5$ & $4-5$ & $4-5$ & $4-5$ & $4-5$ & $4-5$ & $4-5$ \\
\hline
\end{tabular}

Table 12. Rubbing fastness of different fabrics treated with water repellent chemicals at $100 \mathrm{~g} / \mathrm{L}$ conc.

\begin{tabular}{|c|c|c|c|c|c|c|c|c|}
\hline \multirow{3}{*}{ Sample } & \multicolumn{6}{|c|}{ Rubbing fastness } & & \\
\hline & \multicolumn{2}{|c|}{ Unfinished } & \multicolumn{2}{|c|}{ FC } & \multicolumn{2}{|c|}{$\mathrm{FC}+\mathrm{D}$} & \multicolumn{2}{|c|}{$\mathrm{FC}+\mathrm{B}$} \\
\hline & Dry & Wet & Dry & Wet & Dry & Wet & Dry & Wet \\
\hline Rib & $4-5$ & 3 & 4 & $3-4$ & 4 & 3 & 4 & 3 \\
\hline Interlock & $4-5$ & 4 & $4-5$ & 4 & $4-5$ & 4 & $4-5$ & 4 \\
\hline
\end{tabular}


concentrations, gives gradually increased water repellency, regardless of repellent chemical type. From hydrostatic head test, it has clearly seen that the more pressure is required to force water through the fabric after finishing and gradually increasing the conc. from $70 \mathrm{~g} / \mathrm{L}$ to $100 \mathrm{~g} / \mathrm{L}$, the pressure requires more. Rib fabric has higher hydrostatic head test rating than interlock fabric because of rib fabric has higher GSM and more compactness. However, unlike the findings of previous research works which described that if the water repellent was used with higher conc., strength is decreased. The repellent chemicals and their changing conc. did not cause significant change to bursting strength of knit fabrics. There was no remarkable deviation is observed in GSM on the basis of water repellent chemicals and their varying conc. Moreover, fabric's GSM rises due to the mechanical reinforcement by formation of bonds within interfibre and interyarn. It is attributed in decrease of bursting strength and air permeability because of a direct consequence of deposition of a thin film onto or within the fibre. Air permeability of fabric is decreased after water repellent finish because of the restriction effect to the airflow. Air permeability rating of $\mathrm{FC}+\mathrm{B}$ for both rib and interlock fabrics gave comparatively better result than FC and FC + $\mathrm{D}$ water repellent chemicals. A higher in repellent chemical conc. caused a higher wash fastness, water fastness, color fastness to perspiration and rubbing fastness. However, a higher in repellent chemical conc. caused a minor effect on color fastness to chlorinated water. Fabric finishing after dyeing, had no effect on water repellency is another important conclusion of this work.

\section{Acknowledgements}

I should like to express my deep gratitude to MICRO FIBRE for providing me the lab facilities. I should also like to thank Essential Clothing Ltd for providing me sample fabrics. Again special gratitude also goes to the Wet Processing Lab and the TTQC Lab of Bangladesh University of Textiles (Butex).

\section{References}

[1] Bongiovanni, R., Zeno, E., Pollicino, A., Serafini, P.M. and Tonelli, C. (2011) UV-Light Induced Grafting of Fluorinated Monomer Onto Cellulose Sheets. Cellulose, 18, 117-126. https://doi.org/10.1007/s10570-010-9451-5

[2] Castelvetro, V., Francini, G., Ciardelli, G. and Ceccato, M. (2001) Evaluating Fluorinated Acrylic Lattices as Textile Water and Oil Repellent Finishes. Textile Research Journal, 71, 399-406. https://doi.org/10.1177/004051750107100506

[3] Shao, H., Sun, J.Y., Meng, W.D. and Qing, F.L. (2004) Water and Oil Repellent and Durable Press Finishes for Cotton Based on a Perfluoroalkyl-Containing Multi-Epoxy Compound and Citric Acid. Textile Research Journal, 74, 851-855. https://doi.org/10.1177/004051750407401002

[4] Lee, H.J. and Michielsen, S. (2007) Preparation of a Superhydrophobic Rough Surface. Journal of Polymer Science Part B: Polymer Physics, 45, 253-261. https://doi.org/10.1002/polb.21036

[5] Li, Z.R., Fu, K.J., Wang, L.J. and Liu, F. (2008) Synthesis of a Novel Perfluorinated Acrylate Copolymer Containing Hydroxyethyl Sulfone as Crosslinking Group and 
Its Application on Cotton Fabrics. Journal of Materials Processing Technology, 205, 243-248. https://doi.org/10.1016/j.jmatprotec.2007.11.284

[6] Roe, B. and Zhang, X. (2009) Durable Hydrophobic Textile Fabric Finishing Using Silica Nanoparticles and Mixed Silanes. Textile Research Journal, 79, 1115-1122. https://doi.org/10.1177/0040517508100184

[7] Kasturiya, N. and Bhargava, G.S. (2003) Liquid Repellency and Durability Assessment: A Quick Technique. Journal of Industrial Textiles, 32, 187-222. https://doi.org/10.1177/1528083703032003004

[8] Schindler, W.D. and Hauser, P.J. (2004) Chemical Finishing of Textiles. Woodhead Publishing Ltd., Cambridge, 80-82.

[9] Sahin, B. (1996) Fluorochemicals in Textile Finishing. Int. Text. Bull.-Dyeing/Printing/Finishing, 42, 26-30.

[10] Qi, H.J., Sui, K.Y., Ma, Z.L., Wang, D., Sun, X.Q. and Lu, J.J. (2002) Polymeric Fluorocarbon Coated Polyester Substrates for Waterproof Breathable Fabrics. Textile Research Journal, 72, 93-97. 